\title{
As escolas multisseriadas do município de Iguape 1980-2008
}

\author{
Multiseriated schools in the city of Iguape 1980-2008
}

Escuelas multigrado en el municipio de Iguape 1980-2008

Cristiane Corrêa Strieder - Universidade de Sorocaba | Doutoranda do Programa de Pós-graduação em Educação | Sorocaba | SP | Brasil | E-mail: cristrieder@gmail.com | Đorcı

Vânia Regina Boschetti - Universidade de Sorocaba | Programa de Pós-graduação em Educação | Sorocaba | SP | Brasil | E-mail: vania.boschetti@prof.uniso.br | Đorcı

Resumo: Essa pesquisa tem como objetivo abordar o funcionamento das escolas multisseriadas em atividade no município de Iguape. Visa compreender as diferenças dessa forma com as escolas urbanas e reconhecer a importância destas instituições para a comunidade rural. Apesar de focar um local específico, é possível compreender através do estudo a diferença que há entre a educação rural e urbana, diante de um contexto histórico que abrange os setores político, econômico, social e cultural. Essa modalidade escolar, que foi criada no século XIX, continua em funcionamento na atualidade, apresentando em sua estrutura semelhanças significativas com a forma em que funcionava nos séculos anteriores. Nesse ambiente, os alunos de diferentes séries podem permanecer, de forma concomitante, com o mesmo docente. O procedimento metodológico norteou-se pelo levantamento e estudo da bibliografia sobre a história de Iguape, assim como de trabalhos científicos sobre instituições rurais e unidocentes no Brasil, entrevistas e análise da legislação.

Palavras-chave: Escolas multisseriadas. Escola rural. Educação. Iguape (SP).

Abstract: This research aims to address the functioning of multi-grade schools in operation in the municipality of Iguape. It aims to understand the differences in this way with urban schools and to recognize the importance of these institutions for the rural community. Despite focusing on a specific location, it is possible to understand through the study the difference between rural and urban education, in the face of a historical context that encompasses the political, economic, social and cultural sectors. This school modality, which was created in the 19th century, remains in operation today, presenting in its structure significant similarities with the way it worked in previous centuries. In this environment, students from different grades can remain, concurrently, with the same teacher. The methodological procedure was guided by the survey and study of the bibliography on the history of Iguape, as well as scientific work on rural and unidocent institutions in Brazil, interviews and analysis of the legislation.

Keywords: Multigraded schools. Rural school. Education. Iguape (SP).

\footnotetext{
- Recebido em 09 de março de 2020 • Aprovado em 17 de dezembro de 2020 • e-ISSN: 2177-5796
}

DOI: http://dx.doi.org/10.22483/2177-5796.2020v22n3p853-872

Copyright @ 2019. Conteúdo de acesso aberto, distribuído sob os termos da Licença Internaonal da CreativeCommons - CC BY-NC-SA Atribuição Não Comercial (https://br.creativecommons.org/licencas/) - Permite distribuição e reprodução, desde que atribuam os devido créditos à publicação, ao autor(es) e que licenciem as novas criações sob termos idênticos. 
STRIEDER, Cristiane Corrêa; BOSCHETTI, Vânia Regina. As escolas multisseriadas do município de Iguape 1980-2008.

Resumen: Esta investigación tiene como objetivo abordar el funcionamiento de las escuelas aisladas en funcionamiento en el municipio de Iguape. Su objetivo es comprender las diferencias de esta manera con las escuelas urbanas y reconocer la importancia de estas instituciones para la comunidad rural. A pesar de centrarse en una ubicación específica, es posible comprender a través del estudio la diferencia entre educación rural y urbana, frente a un contexto histórico que abarca los sectores político, económico, social y cultural. Esta modalidad escolar, creada en el siglo XIX, sigue en funcionamiento hoy, presentando en su estructura similitudes significativas con la forma en que funcionó en siglos anteriores. En este entorno, los estudiantes de diferentes grados pueden permanecer, al mismo tiempo, con el mismo maestro. El procedimiento metodológico fue guiado por la encuesta y el estudio de la bibliografía sobre la historia de Iguape, así como el trabajo científico sobre las instituciones rurales y unidas en Brasil, entrevistas y análisis de la legislación.

Palabras clave: Escuelas aisladas. Escuela rural. Educación. Iguape (SP). 


\section{Introdução}

O estudo sobre as escolas isoladas multisseriadas é significativo uma vez que diante do processo de modernização pelo qual vem passando a educação, e de políticas que promovem subsídios ao setor, estas instituições, localizadas em pontos de difícil acesso, centradas na zona rural, parecem, em primeiro momento, não participarem de tais considerações, funcionando em condições precárias, tanto no que concerne à estruturação física quanto à pedagógica.

Há controvérsia entre estudiosos da educação que apoiam ou criticam essas pequenas instituições multisseriadas, uma vez que estas escolas incorporam uma clientela, cujo comprometimento do aprendizado evidencia-se principalmente no momento em que os alunos buscam continuar seus estudos nas instituições urbanas.

Perante essa afirmação, há o questionamento: de que forma ocorre esse comprometimento?

Diante dessa realidade deu-se preocupação de estudo sobre esse ambiente escolar tão distinto das escolas situadas na localização urbana do município e a compreensão da importância destas para as comunidades as quais pertencem. Também se considerou a existência da preocupação do trabalhador rural em manter tais instituições em funcionamento nas suas comunidades.

Iguape foi a cidade escolhida como universo de análise, diante de sua riqueza histórica e das diversidades político-econômicas, assim como socioculturais, uma vez que está situada em uma das regiões consideradas mais carentes do estado de São Paulo, o Vale do Ribeira, onde concentra-se número significativo de escolas rurais com classes multisseriadas, ambiente escolar bastante distinto da região central do município.

A análise considerou as características da cidade que motivaram e ainda estimulam a existência das salas em funcionamento. O reconhecimento dos fatores que fundamentam a vivência da cidade auxiliou na compreensão da estrutura e a organização dos setores nesta inseridos, uma vez que estes respondam às exigências sociais, ou mesmo sejam pontos conflitantes entre as classes formadas por diferentes níveis econômicos. A educação não se desvencilha desse processo. 
No contexto situa-se o trabalhador agrícola, principal usuário da modalidade escolar situada na zona rural de tal município. Também foi necessário que se efetuasse uma relação dessas pequenas instituições com os fenômenos sociais, políticos, econômicos, ambientais e culturais que as permeiam.

A pesquisa abrangeu um período de 28 anos, de 1980 a 2008, o que foi possível, por meio de fontes primárias, mas também por relatos e entrevistas com alunos e pessoas que estiveram ou ainda estão envolvidos nesse contexto. Apesar do recorte temporal, muitas dessas escolas ainda funcionam nos bairros mais distantes da cidade.

A colaboração de funcionários da Secretaria Estadual de Educação de São Paulo e de membro da Secretaria Municipal de Educação de Iguape ofereceram uma perspectiva mais próxima da realidade sobre a organização e funcionamento das escolas multisseriadas na atualidade.

Outro aspecto relevante para a compreensão da educação nas salas unidocentes está no entendimento do que são, como surgiram e ainda se desenvolvem, pois diante da legislação e dos parâmetros que definem o funcionamento dessas escolas, foi possível visualizar os fatores integrados na educação do homem trabalhador campesino. Pela estrutura da proposta pedagógica e das ações que interferem no processo ensino-aprendizagem pode-se esclarecer as distinções que ocorreram em um mesmo setor público de quando este atua no meio urbano e quando no rural.

As considerações sobre a importância social dessas escolas como formas de expansão da educação para os habitantes das zonas mais distantes do centro urbano, assim como suas funções como meio de integração da comunidade, mediante possíveis eventos lá efetuados, também são relevantes para que se possa traçar conclusões sobre os motivos que levam ao seu funcionamento.

A possibilidade das crianças residentes distantes do centro urbano poderem estudar dentro de sua comunidade e a relação desse vínculo como estímulo de permanência desses estudantes em seu ambiente são essenciais para a valorização das regiões agrícolas e do homem pertencente a essas localidades. Portanto, a aprendizagem escolar tem papel fundamental no que se refere ao êxodo.

Essa síntese pretende apresentar os principais elementos que compuseram a pesquisa explicando sobre os elementos históricos, sociais, culturais e referentes à educação de Iguape, o 
conceito de escolas multisseriadas e os resultados obtidos através de pesquisa empírica sobre e sua importância dessas instituições para o povo ribeirinho.

\section{Iguape: história, sociedade, educação e cultura}

O reconhecimento de algumas informações relativas ao município de Iguape, como sua formação social, política, econômica e cultural é relevante para análise das escolas multisseriadas.

Iguape é um município brasileiro que se situa no litoral Sul do Estado de São Paulo, na Região do Vale do Ribeira conforme apresenta Pereira Junior. (2005, p. 9). Em área, é considerado o maior município paulista. A população iguapense, conforme dados do IBGE (2017), alcançou em 2010, último censo, um total de 28.841 habitantes.

Essa região litorânea apresenta características contraditórias que fomentam não apenas sua história, como os aspectos socioculturais e econômicos.

Atualmente, a cidade de Iguape ainda possui comunidades isoladas de povos de origens distintas, como indígenas, negros e ribeirinhos. Este fato estimula o turismo, pois nas áreas mais altas é comum a habitação de comunidades indígenas, já bastante descaracterizadas pelo relacionamento de seus membros com os caiçaras e com as comunidades urbanas. A Fundação Nacional do Índio (2008) menciona que eram 45 indígenas guaranis morando entre Iguape e Cananéia em 2008.

Mesmo com a degradação ambiental, atualmente Iguape é composta por quase uma centena de bairros e comunidades diversificadas, que contribuem por sua riqueza cultural. Segundo dados extraídos do site Quilombos do Ribeira (2011), o maior número de comunidades quilombolas de todo o estado de São Paulo está no Vale do Ribeira. A elas acrescentam-se índios guaranis e caiçaras o que resulta em diversidade cultural muito próximas à região urbana. Essas comunidades que somam 2.456 famílias estão situadas entre Iguape, Cananeia e Paranaguá, numa extensão de 140km.

Nas ocasiões de comemorações ou festividades, o trabalhador da zona rural integra-se à sociedade urbana, e por momentos, o povo parece se unir e voltar a um único objetivo de comemorar, ainda que a divisão de classe esteja visível seja no vestuário, no vocabulário, nas ações de um modo geral. Rolnik (1988, p. 24) aponta a relevância destes eventos: 


\begin{abstract}
Nestes momentos, assim como o carnaval ou as festas religiosas, as muralhas invisíveis que regulam a cidade, mantendo cada coisa em seu lugar e comprimindo a multidão do dia-a-dia, se salientam pela ausência. Quando o território da opressão vira cenário de festa, é a comunidade urbana que se manifesta como é: com suas divisões, hierarquias e conflitos, assim como com suas solidariedades e alianças. Na hora do rito, isso vem à tona; mas no dia-a-dia tudo isso está presente, subjacente, nos gestos e palavras cotidianas dos habitantes da cidade.
\end{abstract}

No entanto, no cotidiano, a falta de planejamento e consideração sobre a situação de sobrevivência do povo ribeirinho faz com que muitas comunidades não se estabeleçam em suas localidades, sendo obrigadas a buscar outros lugares para residir.

Por esses motivos e com as enchentes que ocorreram em 1983, muitos ribeirinhos deixaram suas terras e buscaram a zona urbana, instalando-se no bairro do Rocio, à margem do Rio Ribeira, contrária à zona comercial.

Por esse fato, pode-se perceber que o povo mais carente do município não conseguia manter-se instalado por muito tempo em um mesmo local, o que quebra, principalmente, suas estruturas social, econômica e política, se assim, como esclarece Rolnik (1988), ficar entendido que ser habitante é também participar da vida pública, ainda que esta participação seja de cumprimento de regras, ou mesmo de submissão às normas estabelecidas. A cidade compreende a organização espacial, social, econômica, e esta organização é política.

A mesma autora esclarece este fenômeno quando conceitua a cidade como

[...] fruto da imaginação e trabalho articulado de muitos homens, a cidade é uma obra coletiva que desafia a natureza.

Ela nasce com o processo de sedentarização e seu aparecimento delimita uma nova relação homem/natureza: para fixar-se em um ponto para plantar é preciso garantir o domínio permanente de um território (ROLNIK, 1988, p. 66).

O bairro do Rocio pode ter sido escolhido por aqueles que buscavam espaço para estabelecer moradias, uma vez que não tinham condições de habitar no centro urbano de Iguape devido ao alto valor dos imóveis.

Assim, como não atendia as expectativas da classe superior, o bairro foi praticamente ignorado, levando seus habitantes a enfrentar grandes problemas, conforme aponta pesquisa feita pela Secretaria Estadual da Saúde. Iversson (1983) esclarece que o centro urbano de Iguape estava separado por um canal artificial, de um bairro que se tratava do Rocio e que se apresentava em situação precária, com ruas cobertas de gramínea, onde o calçamento não chegou. 
O Rocio acabou se expandindo de forma descontrolada, o que acarretou problemas, inclusive pela escassez de saneamento.

Nas duas últimas décadas, no entanto, vem se acentuando a ocupação da área, intensificando-se os investimentos turísticos e a migração do campo para a cidade o que provocou uma ocupação desordenada do espaço urbano, trazendo consigo diversos problemas ambientais, como a contaminação de corpos d'água por deficiência de saneamento básico etc. (ROCHA; FORESTI, 1998).

Para que os habitantes pudessem atravessar do Rocio para o centro, ou vice-versa, era necessário o uso de canoas. Esses transportes foram substituídos por uma pequena balsa, “ferryboat". Somente em 1986, conforme esclarece Pereira Junior (2005), é que a passarela que liga o centro àquele bairro foi construída, fato que auxiliou de forma relevante a vida prática e econômica dos habitantes carentes.

Dizem que a história do Rocio pode ser dividida em antes e depois da passarela, tamanha a importância àquele bairro. [...] Após o encerramento dos serviços de balsas no Valo Grande, a travessia de pedestres era feita em catraias (tipo de embarcação) em que eram cobradas tarifas pela travessia, sacrificando economicamente a população (PEREIRA JUNIOR, 2005, p. 83).

Portanto, se de um lado do Rio Ribeira há um centro urbano, com infraestrutura adequada para atender a seus cidadãos e que parece preservar através da arquitetura colonial os mesmos valores da burguesia que habitou Iguape em seu período mais rico, no século XVIII, na margem oposta a realidade é claramente contrária, pois evidencia o declínio e degradação do homem de baixa renda e seu meio.

É de se notar que a pouca estrutura do Rocio aponta para uma divisão das classes sociais, principalmente quando comparada ao centro, onde ainda estão presentes as fortes marcas de passado economicamente próspero. Lefebvre (1969, p. 12) explica que "esses núcleos resistem ao se transformarem. Continuam a ser centros de intensa vida urbana. As qualidades estéticas desses antigos núcleos desempenham um grande papel na sua manutenção”.

Assim, o órgão dirigente do município preocupado em manter vivo o semblante da prosperidade central pareceu pouco se preocupar, até a primeira década do século XXI, em restituir a dignidade dos agricultores, ou demais trabalhadores, separando-os dos mais abastados não só pelas condições precárias de vida, mas também por um acidente geográfico: um rio.

Diante dessa realidade, muitos ribeirinhos optaram em permanecer na zona rural, distante da cidade. 
Analisando todos estes fatores que englobam progresso e degradação, há de se lembrar de que se no século XVIII a ação comercial estimulou a fluidez do capital e o crescimento econômico na ânsia de lucro imediato, esta não previu o prejuízo que estaria por vir quando ampliou parte do rio, o chamado Valo Grande, para facilitar o trânsito de produtos por via aquática.

A cidade, que chegou a ocupar posição de destaque no mercado europeu como exportadora de arroz, pôde assistir em pouco mais de um século a própria decadência, seja econômica, social ou mesmo afetiva, uma vez que muitos iguapenses não conseguiam constituir laços estreitos com a terra ou com sua comunidade, por terem de abandoná-las constantemente devido às inundações.

Durante o século XIX e XX, o turismo, a pesca e a agricultura foram fontes básicas de economia da região, principalmente no que se pode usufruir do ambiente marinho, uma vez que a localização da cidade possui extensa faixa litorânea. Mas a agricultura e pecuária também auxiliaram para a subsistência.

Dentre as atividades agropecuárias do Vale do Ribeira destacam-se a banana e a pastagem (natural e cultivada). Ao longo dos anos tem havido introdução de novas culturas no Vale do Ribeira, propiciando maior diversificação agrícola e incremento na produção, principalmente em estabelecimentos de pequenos e médios produtores. Podese verificar também que algumas culturas ampliaram significativamente a sua participação entre 2002 e 2006, destacando-se: café, pupunha e milho (ANAFALOS, MODOLO, TUCCI, 2007, p. 39-40).

Com esse quadro socioeconômico entende-se que a cidade possuía boa parte da população também em regiões rurais, compostas por pequenas comunidades, geralmente distantes umas das outras, com baixo número de habitantes.

Essa situação justifica a não criação de escolas seriadas, uma vez que não havia número suficiente de crianças em idade escolar nessas regiões situadas às margens da rodovia Pref. Casimiro Teixeira, que liga a cidade de Miracatu a Iguape, ou mesmo a alguns quilômetros desta pista.

Tal rodovia ainda é essencial para a locomoção destas comunidades distantes, mas tornase intransitável nos períodos chuvosos devido às enchentes, o que pode explicar um dos motivos de existir uma quantidade significativa de escolas multisseriadas, localizadas nos bairros mais distantes do centro urbano. Rolnik (1988, p. 61) incita para a reflexão de que "a construção de 
instituições fechadas e isoladas procura confinar, sob vigilância permanente, uma população marginal, que desafia e ameaça a fluidez da máquina cidade".

Conclui-se, pela existência de escolas tão distantes, que um dos fatores que mais se contrapõem entre os habitantes de Iguape é a questão educacional.

Esse setor social se dispõe de forma contrastante que se justifica por ter sido o município contemplado com um dos primeiros grupos escolares paulistas, o colégio Vaz Caminha, (antes dividida em dois prédios, um para meninos e outro para meninas), e que passou em 1917 a funcionar em vultosa construção, que até os dias de hoje mantém-se preservada ainda como estabelecimento de ensino.

Atualmente, ainda há no território iguapense 21 registros (QEDU, 2017) de escolas em funcionamento na zona rural, tanto municipais que atendem o $1^{\circ}$ ciclo do ensino fundamental, como estaduais.

\section{Escolas multisseriadas de Iguape}

A maior dificuldade para se compreender a criação das escolas multisseriadas de Iguape está na falta de documentos que comprovem a existência desses estabelecimentos de ensino antes da década de 80, pois conforme informações da Secretaria Estadual de Educação de São Paulo (2012) o ato de criação dessas escolas origina-se a partir desse período.

A Prefeitura Municipal de Iguape (2012) também não tem informação sobre essas salas, uma vez que não há nenhum registro desses prédios, nem mesmo uma planta, um croqui que indiquem informações antes de seus atos de criação.

Em Iguape, especificamente, Young (1903, p. 250) explica que "são poucos os proprietários de terras neste município que possuem mapas dos seus terrenos aprovados pelo Governo". O pesquisador ainda acrescenta que

Não nos é lícito duvidar que a maior parte das terras deste município fosse adquirida simplesmente por posse usucapiana, e que essas terras mais tarde fossem partilhadas entre herdeiros dos primitivos possuidores, ou vendidas, ficando desta arte os novos habitantes com documentos comprobatórios do seu domínio, e, assim é que neste mnicípio, a despeito de sua enorme extensão, poucos terrenos devolutos atualmente existem. [...] alguns registros existem relativos a extensões enormes de terrenos, dos quaes os registrantes não declararam de modo algum como é que os possuíam, e em cujos terrenos não existia naquele tempo mais que um ou dois alqueires de terras em cultura, sendo o resto coberto de matas virgens (Young, 1903, p. 249). 
Diante deste esclarecimento é quase impossível descobrir a origem das escolas multisseriadas, o local exato e a data em que começaram a funcionar, pois a maioria está fixada em terrenos emprestados ou doados por algum fazendeiro ou dono de terras que tinha interesse em instruir a comunidade local.

Em alguns casos, como do bairro do Retiro, ainda existem estacas no chão que mostram a antiga localização da sala antes de uma nova construção, edificada poucos metros adiante.

Em entrevistas feitas com a comunidade rural, a população local comentou que havia escolas em regiões distantes do centro da cidade "há muito tempo" e que essas escolas existiram antes de uma nova estrutura e organização. Young (1903, p. 249) explica que

Pelo estudo das cartas de sesmarias pode-se conhecer a expansão do povo para o interior desta zona, começando dos estabelecimentos próximos à Vila e extendendo-se gradualmente, a internar-se cada vez mais, porém acompanhando sempre o rio Ribeira e seus afluentes, especialmente os rios Uma e Peroupaba. Era natural que o povo procurasse as margens do majestoso rio Ribeira, para ali fundar estabelecimento, em virtude da facilidade do solo das margens ribeirinhas. Logo que essas terras se achavam povoadas, naturalmente eram procurados os diversos afluentes do Ribeira que facultassem os mesmos meios de transporte.

Diante da explanação de Young (1903), pode-se entender como os bairros afastados do centro nasceram e se desenvolveram com a agricultura. O povo precisava utilizar embarcações para transportar os produtos que cultivavam em suas terras, uma vez que o transporte terrestre ainda não estava em desenvolvimento naquela localidade. Esse fato auxiliou na criação de escolas multisseriadas.

Pode-se deduzir que para os filhos de colonos adquirirem instrução, se esta fosse do interesse dos senhores do arroz ou mesmo da Igreja, deveriam frequentar uma escola local, uma vez que os meios de transportes aquáticos eram mais usados para levar cargas e mercadorias e não funcionavam diariamente ou com frequência.

Assim, acredita-se que algumas salas de aula foram adaptadas nesses bairros mais distantes. Mas Fortes (2000, p. 181) menciona que desde o século XVI Iguape já possuía escola ministrada pelos jesuítas na região central:

[...] É correto afirmar que os rudimentos de primeiras letras eram ministrados pelos jesuítas, que chegaram a construir uma casa na vila, uma espécie de capela, hoje, muito propriamente, chamada de Casa dos Jesuítas, ainda existente ao lado esquerdo da Igreja de São Benedito, na Rua D. Idílio Soares. 
O autor ainda esclarece que em meados do século XIX, com a expansão comercial, algumas escolas isoladas de primeiras letras situavam-se no município, nos bairros da Enseada, por ser mais populoso, e no Porto do Ribeira uma sala para meninas. Ele complementa que "nesse período, o ensino de primeiras letras teve algum progresso, apesar de ainda estar muito aquém das necessidade, existindo cadeiras em bairros rurais, como Icapara, Engenhos, Juréia, Enseada, aquém do Porto do Ribeira (FORTES, 2000, p.183)”.

Com a reforma educacional que desenvolveu a unificação das classes isoladas, as salas que funcionavam nos bairros mais próximos do centro de Iguape passaram a constituir um grupo escolar na zona urbana, no ano de 1894, fato este que comprova a existência dessas escolas e a preocupação que havia com a educação naquela época: O Grupo Escolar de Iguape, que na época ainda não funcionava em prédio próprio.

Porém, a população contou em entrevista que quando ocorreram as primeiras enchentes provenientes da abertura do Valo Grande, os ribeirinhos buscaram alternativas de sobrevivência no interior da cidade através da agricultura de subsistência. Algumas comunidades construíram salas em terrenos doados, ou mesmo usaram locais em fazendas ou igrejas como instituições de educação, atendendo as crianças que ali residiam.

Os estudantes da região rural recebiam uma educação extremamente distinta das escolas da zona urbana, adequada às suas comunidades, compostas por escolas unidocentes, existentes em seus bairros, instituições com organização bastante semelhante às escolas isoladas do período imperial.

Como exemplo, apresentam-se os bairros de Povoa, Pé da Serra e Costão do Despraiado onde, conforme Iversson et al. (1983, p. 424-425), há uma escola entre a mata:

Localizada a $78 \mathrm{~km}$ de Iguape e a 33 da mesma rodovia por uma pequena estrada não pavimentada e não transitável na época de chuvas, está construída em um espaço aberto em mata densa. Os alunos moram junto ao local ou até a uma distância de 30 minutos de caminhada, em casas situadas dentro da área florestal.

A autorização para uma escola multisseriada passar a funcionar, em primeiro momento, parte da solicitação de sua construção feita por uma comunidade de um bairro afastado. Logo, a Diretoria de Ensino, responsável pelo município no qual esse bairro se estabelecia, analisava o número de crianças em idade escolar ( $1^{\mathrm{a}}$ a $4^{\mathrm{a}}$ séries $)$ e a distância em que se encontram da escola mais próxima. 
Em caso da instituição escolar não estar próxima o suficiente, ou as condições de estradas e vias encontrarem-se em estado precário dificultando a condução dos alunos, opta-se pela construção de uma sala multisseriada, que atenda um mínimo de 15 alunos, conforme já estipulava estipula a Lei 5.822 de 1960, (BRASIL, 1960).

Contudo, muitas vezes, a Lei 5.822 de 1960, (BRASIL, 1960) acaba sendo interpretada como "caso omisso", em que diante de algumas situações uma comissão de supervisores, depois de analisar as solicitações através de uma justificativa, concede ou não autorização em caráter excepcional para que algumas escolas multisseriadas funcionem com menos alunos do que estipula a legislação, considerando a necessidade da comunidade.

Conforme explicação dos supervisores da Diretoria de Ensino da Região de Votorantim (2010), isso ainda é muito comum e não é ação ilegal, uma vez que favorece a sociedade. Para Bastos (2007), há um princípio superior na legislação ou nas determinações jurídicas para situações peculiares, considerando o direito do cidadão acima da lei propriamente, uma vez que se priorize as situações sociais que possam requerer uma norma especial, o que justifica o caso omisso.

Em Iguape o número de crianças matriculadas em algumas escolas rurais multisseriadas é menor que o estipulado. Esse fato mostrou-se positivo, pois assim se entendeu que o interesse do povo é prioridade.

A Lei no 8.069/90, Cap. IV, Art. 53, também pode ser interpretada como forte aliada ao funcionamento dessa modalidade de instituição unidocente situada distante da zona urbana, pois determina: "é direito fundamental da criança e do adolescente, o acesso à escola pública e gratuita próxima de sua residência” (BRASIL, 1990).

Outro fator que importou para o poder público, foi evitar o êxodo. Essa medida está relacionada com a permanência destas escolas na zona rural, pois, segundo os trabalhadores dessas comunidades, se não houvesse escolas na região os filhos, teriam que estudar na cidade. Devido à distância que em algumas localidades chega a quase $100 \mathrm{~km}$ e à falta de condução, as famílias acabariam sendo forçadas a se mudarem para mais próximo do centro urbano.

Por outro lado, os alunos que se dirigiam à zona urbana acabavam buscando se fixar lá, uma vez que o cansaço do percurso diário, a possibilidade de trabalho e as inovações que acontecem nesse lado da cidade são bastante atrativas para os jovens. Lefebvre $(1969$, p. 12) 
explica que "geralmente a juventude, grupo etário, contribui ativamente para essa rápida assimilação das coisas e representações oriundas da cidade”.

Assim, políticas para estimular a fixação do jovem em sua comunidade são necessárias a começar pela Educação, pois conforme esclarecido na II Conferência Nacional por uma Educação no Campo (2004), “os mais altos índices de analfabetismo estão no campo”. Esse fato acaba por incentivar que os alunos da área rural sigam para a cidade.

Mas investir em escolas rurais não parece ser processo tão burocrático, e esta é uma maneira de solucionar o problema pelo qual passam os habitantes do campo. Nádia Cardoso, funcionária da Secretaria Municipal de Educação de Iguape, explicou, em entrevista efetuada em janeiro de 2008, que montar uma escola multisseriada é muito fácil:

[...] é só entrar no sistema da PRODESP, digitar o local e o nome de uma escola [...] isso depois que a solicitação da comunidade é avaliada pela própria Secretaria Municipal de Educação [...] antes a solicitação era encaminhada à Diretoria de Ensino do Estado...hoje, com a municipalização, é o município quem decide (informação verbal).

Mas nem todos concordam com a forma como essas instituições funcionam. Diante da necessidade do homem rural ao acesso à educação, essas escolas deveriam ser reformuladas para uma educação de qualidade.

Acredita-se que por serem unidocentes, estas escolas não preparam adequadamente os alunos, pois como os professores não recebem cursos específicos para trabalharem com séries distintas simultaneamente, não conseguem atender adequadamente aos alunos.

Porém, ainda que exista disparidade pedagógica e estrutural, muitas comunidades se beneficiam dessas salas para eventos culturais, como organização de festas juninas e religiosas, organização de ações beneficentes, entre outras atividades. Também é nesse espaço que ocorrem, muitas vezes, os encontros com palestrantes de outras áreas como a da Saúde, e visitas de entidades políticas.

Em entrevistas feitas com a comunidade rural (2010), 70\% concordou que as escolas nessas regiões são importantes para suas crianças, que acabariam sem efetuar o ciclo I do Ensino Fundamental, se tivessem de ir às escolas situadas na zona urbana.

Fagundes e Martini (2003) apontam que "as comunidades no interior do estado estavam organizadas em torno de igreja, escola, campo de futebol e salão de festas, tendo a escola como 
meio de referência intelectual, e o professor desempenhando papel semelhante ao do "intelectual orgânico".

Em Iguape essa situação manteve-se nas comunidades rurais. As escolas multisseriadas serviam e ainda servem, muitas vezes, para reuniões e eventos culturais, como festa junina e bailes de carnaval, por exemplo. São os próprios moradores e professores que organizam a escola nessas datas, pois conforme relato de alunos, não há funcionários da prefeitura que mantenham o espaço das escolas limpo, carpido, organizado.

Essa realidade também foi citada por moradora do bairro Barra das Areias (2010). Ela se responsabilizava pelo preparo da alimentação, pela limpeza e conservação da sala escolar. A mesma afirmou que caso não fizesse a merenda, as crianças somente lanchariam, a saber que nem sempre a professora organizava-se para prepará-la. Também mostrou que a escola poderia ser mais bem conservada se houvesse vontade dos outros moradores, pois a região era infestada por morcegos e uma das salas não podia ser usada devido ao excesso de excrementos deixados por esses animais.

Uma vez atentos à precariedade das escolas unidocentes, foi considerada a Lei 9.394/96 de Diretrizes e Bases da Educação Nacional, Art. 211, Cláusula Primeira, recomendando a descentralização do ensino e a municipalização dessas salas:

Do Objeto o presente Convênio tem por objeto a ação compartilhada entre a SECRETARIA e o MUNICÍPIO visando a implantação e o desenvolvimento do Programa de Ação de Parceria Educacional Estado-Município para o atendimento ao ensino fundamental, tendo por finalidade a melhoria e expansão do Ensino Público Fundamental, propiciando a todas as crianças condições de real acesso à escola e que nela permaneçam e progridam, atendendo ao disposto nos artigos 211, 212 e 213 da Constituição Federal e no artigo 240 e nos $\S \S 1^{\circ}$ e $2^{\circ}$ do artigo 249 da Constituição Estadual (BRASIL, 1996).

Assim, Iguape aderiu à municipalização, e as escolas que na época tinham o de $1^{\mathrm{a}}$ a $4^{\mathrm{a}}$ séries, a partir de 2003 passaram à responsabilidade parcial do município.

LEI $n^{\circ} 1.685 / 03$ de 03 de fevereiro de 2003 autoriza o poder executivo municipal a celebrar convênio com o governo do estado de São Paulo, por intermédio da secretaria da educação, objetivando a municipalização do ensino fundamental de $1^{\mathrm{a}}$ a $4^{\mathrm{a}}$ séries da E.E. Vaz Caminha, exceto as classes especiais, e $1^{\mathrm{a}} \mathrm{s}$ séries da E.E. Bairro do Rocio, e dá outras providências (IGUAPE, 2003).

No entanto, esse processo não ocorreu de forma simultânea, mas em curto prazo. 
Após a municipalização, certas providências para melhor controlar estas unidades escolares foram tomadas. Era na escola central Vaz Caminha que aconteciam as reuniões pedagógicas, a organização das matrículas, distribuição de material pedagógico das escolas rurais. No sentido de auxiliar na administração dessas salas multisseriadas, duas escolas de bairros mais próximos passaram a ser as responsáveis pelas reclamações e solicitações das comunidades, assim como encontro de professores.

Mesmo assim, em entrevista com Nádia Cardoso, funcionária responsável pelo setor de educação do município, esta esclareceu ser com o próprio Secretário Municipal de Educação, ou com algum funcionário competente desta mesma Secretaria, que o povo busca respaldo sobre os problemas que enfrenta em relação às questões educacionais, ainda que nem sempre possa ser atendido e assim tenha que tomar suas próprias providências para assegurar o funcionamento satisfatório da unidade escolar de sua comunidade.

Apesar de as escolas multisseriadas terem sido municipalizadas, cada uma mantém sua peculiaridade. Cada bairro, cada comunidade, pertence a realidades diferentes, com suas características singulares, mas, apesar das especificidades, é unânime a importância dessas instituições em todos esses locais.

\section{Considerações}

A cidade de Iguape passou por constantes períodos de desenvolvimento econômico, como os ciclos do ouro, da navegação, do arroz e de outras agriculturas, mas também foi marcada pelos desastres ecológicos causados pela abertura do Valo Grande, no rio Ribeira, levando não só a economia, assim como o setor da educação a atravessarem crises e modificações.

O descontrole político diante das inundações desencadeou novo prisma econômico, que influenciou entre outros setores sociais, a educação, uma vez que o trabalhador rural não podia mais permanecer nas zonas de alagamento, voltando-se para o interior, onde desenvolveu a agricultura de subsistência.

Por volta da década de 80, diante do programa de "Educação para Todos" desenvolvido pelo Estado, uma vez que algumas famílias conseguiram se fixar nestas áreas isoladas houve necessidade de contemplá-las com escolas multisseriadas, possibilitando, assim, que o homem 
rural também participasse da educação. Diante desse fato, poder-se-ia acreditar que a educação escolar pública estava sendo ampliada a ponto de atender à sociedade de modo geral, se a precariedade pelo qual estas pequenas salas unidocentes, organizadas naquelas regiões mais distantes, não fosse tão gritante.

Principalmente no que diz respeito à Iguape, onde não há pesquisas ou estudos sobre a realidade dessas instituições, foi possível comprovar que houve pouca preocupação com a escola multisseriada. Esse desinteresse justifica a demora da intervenção das autoridades políticas para esse setor.

Dificuldade de transporte e o difícil acesso viário contribuíram para as constantes faltas dos professores, o que compromete o processo ensino-aprendizagem, além da estrutura física desqualificada das salas que favoreceu a concepção de debilidade dessas instituições.

A escassa política de programas para o desenvolvimento do processo ensinoaprendizagem, uma vez que não eram oferecidos cursos ou capacitação aos professores que ministrava aulas para quatro turmas de séries distintas na mesma sala, foi outro fator de extrema importância no desenvolvimento das atividades escolares, pois o despreparo profissional para assumir turmas em níveis diferentes comprometia o rendimento dos alunos.

Há de se considerar que todas as inovações pedagógicas necessitam de capacitação para serem adequadas ao processo ensino-aprendizagem, por isso a necessidade do professor ter preparo para acompanhá-las.

Essas situações são algumas das muitas que justificam a ótica daqueles que não aprovam as escolas multisseriadas, pois, ainda que ocorra a intenção de apoio a estas instituições, na prática, essas ações nem sempre acontecem.

As escolas da zona rural iguapense, enquanto estavam vinculadas a uma instituição central, participavam do mesmo currículo desta, não abrangendo a cultura e o trabalho rural, não relacionando o ensino das crianças dessas comunidades com a terra a que pertenciam.

Por outro lado, pôde-se ver que as comunidades rurais não se mostravam passivas diante das questões educacionais, pois os alunos e suas famílias é que mantinham ligação direta com as instituições unidocentes e participavam das ações educacionais em busca de soluções para seus problemas diretamente na Secretaria Municipal de Educação, conforme explicou Nádia Cardoso, a funcionária responsável pelo setor. 
A atuação do homem rural quanto à "exigência" da abertura de escola, ainda que o número de crianças não atingisse o necessário para o funcionamento de uma instituição de ensino, também comprovou essa mobilização.

Apesar dos obstáculos que impactavam o processo ensino-aprendizagem de forma paradoxal, estes também foram fortes representantes das manifestações dos trabalhadores rurais, que lutavam pela educação de seus filhos, reivindicando seus direitos sobre a cidadania, pois através das visitas constantes feitas à Secretaria Municipal de Educação, assim como as preocupações sobre as escolas de suas comunidades apresentadas nas entrevistas, foi possível perceber uma face participativa na educação.

As comunidades compreenderam a necessidade de educação escolar próxima de casa devido ao número de jovens que necessitava estudar e que pela pouca idade não poderia ir ao centro da cidade devido à distância. Assim, as escolas nessas regiões eram importantes para suas crianças, que acabariam sem efetuar o ciclo I do Ensino Fundamental se tivessem de ir aos colégios situados na zona urbana.

Por meio do resultado das entrevistas e da observação das ações do trabalhador rural relativas à Educação, concluiu-se que este poderia não reconhecer a necessidade de uma mudança política para um aprendizado de qualidade e significativo, mas não deixou de lutar pelo direito à escola como melhores oportunidades para seus descendentes.

Foi diante das reivindicações das comunidades agrícolas que estas buscaram dar sentido à sua história, ainda que não fossem ações conscientes e efetivamente direcionadas a essa intenção.

As escolas multisseriadas, instaladas nas zonas de difícil acesso, são palco dessas manifestações, desde o momento em que seu espaço foi buscado para a incorporação de um aluno, até as cobranças de melhorias, ou mesmo participações comunitárias para a conservação deste patrimônio, conforme declarado nas entrevistas com moradores das comunidades rurais, professores e depoimento dos funcionários da Secretaria Municipal de Educação de Iguape.

Esse quadro possibilitou a percepção da organização da classe trabalhadora por uma participação social inclusiva.

Essas comunidades puderam quebrar, com ações significativas que visavam fortificar seus valores culturais, a concepção conservadora de que só a elite é participante ativa de um processo histórico, mediante o poder capital. Para isso, foi preciso a permanência do homem em seu meio, sem carências ou privações que o estimulassem a abandonar a terra à qual pertence. 
Dessa forma, ficou evidente a necessidade da criação e manutenção de centros de atendimento à saúde, segurança e outros setores que possibilitem dignidade para a vida do trabalhador rural, principalmente educação.

Especificamente sobre Educação, as alterações pedagógicas devem ser repensadas, de forma particular, sobre a prática do educador que ministra aulas nesse ambiente. Este tem importância relevante, pois é um elemento que deve incentivar a conservação da identidade histórica, para que não haja ruptura entre a valorização inserida nas ações comunitárias com os conceitos apontados mediante a prática docente.

Também é o professor quem pode transformar a ótica do aluno ou auxiliá-lo na conscientização do significado da verdadeira educação e valorização de seu meio, pois de um modo geral, quando se busca resgatar o homem ribeirinho, as comunidades quilombolas ou indígenas que habitam o local são muitas vezes apresentadas como alegorias culturais que marcam as variações linguísticas, as atividades artesanais e outros aspectos que definem a cultura, geralmente valorizados pelo turismo que busca originalidade.

Mas o homem do campo, ainda que marginalizado pela urbanização, é responsável pela constituição da história local. As escolas multisseriadas não aconteceriam se as comunidades situadas no interior do município não existissem.

Esse povo não é mero espectador, mas protagonista da sociedade à qual pertence. Através da história da cidade e da análise das instituições rurais, foi possível compreender sua organização e fazer o reconhecimento dos habitantes da zona rural na luta pelo exercício de sua cidadania, principalmente quando recorrem à educação como força que impulsiona seus descendentes para condições mais dignas de vida e igualitárias diante da sociedade urbana.

\section{Referências}

ANAFELOS, A. C.; MODOLO, V. A.; TUCCI, M. L. S. Expansão do cultivo da pupunheira no Vale do Ribeira, estado de São Paulo, 2002-2006. Informações Econômicas, São Paulo, v.37, n.10, p.37-43, out. 2007.

BASTOS, J. J. C. Interpretação e analogia em face da lei penal brasileira: visão teórico-dogmática e crítico-metodológica. Publicado em julho de 2007. Disponível em:

https://jus.com.br/artigos/10130/interpretacao-e-analogia-em-face-da-lei-penal-brasileira. Acesso em: 8 jan. 2019. 
BRASIL. Lei $\mathbf{n}^{\circ} \mathbf{5 . 8 2 2}$ de 16 de ago. 1960. Dispõe sobre a criação e instalação de escolas de emergência, e dá outras providências. Brasília: Secretaria de Estado dos Negócios do Governo, 1960. Disponível: https://www.al.sp.gov.br/repositorio/legislacao/lei/1960/lei-5822-16.08.1960.html. Acesso: 9 jan. 2019.

BRASIL. Lei no 8.069 de 13 jul. 1990. Dispõe sobre o Estatuto da Criança e do Adolescente e dá outras providências. Cap. IV, Art.53. Brasília: Secretaria de Estado dos Negócios do Governo, 1990.Disponível em: http://www.planalto.gov.br/ccivil/LEIS/L8069.htm. Acesso em: 9 jan. 2019.

BRASIL. Lei No 9.394, de 20 de dezembro de 1996. Estabelece as diretrizes e bases da educação nacional. Brasilia: Casa Civil, 1996. Disponível: http://www.planalto.gov.br/ccivil_03/leis/19394.htm. Acesso: 9 jan. 2019.

CONFERÊNCIA NACIONAL POR UMA EDUCAÇÃO NO CAMPO, 2., 2004, Luiziânia, GO. Declaração final (Versão Plenária): por uma política pública de educação do campo. Disponível em: http://www.dominiopublico.gov.br/download/texto/me4537.pdf. Acesso: 25 jan. 2019.

FAGUNDES, J.; MARTINI, A.C. Políticas educacionais, da escola multisseriada à escola nucleada: o impacto cultural e educacional da extinção das escolas multisseriadas. Olhar do Professor, Ponta Grossa, n. 6, n. 1, p. 99-118, 2003. Disponível em: https://www.redalyc.org/pdf/684/68460108.pdf. Acesso em: 9 abr. 2019.

FORTES, R. Iguape, nossa história. São Paulo: Soset, 2000. v.1.

FUNDAÇÃO NACIONAL DO ÍNDIO. Funai conclui processos de demarcação das Terras Indígenas Cobra Grande (PA) e Guaviraty (SP). Brasília: FUNAI, 20 de dezembro de 2008. Disponível:

http://www.funai.gov.br/index.php/comunicacao/noticias/5161-funai-conclui-processos-de-homologacaodas-terras-indigenas-cobra-grande-pa-e-guaviraty-sp . Acesso: 9 jan. 2019.

IGUAPE. Lei no 1.685/03. Iguape: Prefeitura Municipal; Portal público, 7 de maio de 2003. Disponível em: https://iguape.sp.leg.br/leis/legislacao-municipal-1/2003/2003/1-1-685.pdf. Acesso em: 22 nov. 2008.

IBGE - INSTITUTO BRASILEIRO DE GEOGRAFIA E ESTATÍSTICA. Cidades e estados - Iguape. Brasília: IBGE, 2017. Disponível em: https://www.ibge.gov.br/cidades-e-estados/sp/iguape.html. Acesso 22 jan. 2019.

IVERSSON, L. B. et al. (org.). Estudos sorológicos para pesquisa de anticorpos de arbovírus em população humana da região do Vale do Ribeira IV- Inquérito em escolares residentes no município de Iguape, SP (Brasil). Revista de Saúde Pública, São Paulo, v. 17, n. 6, p. 423-435, dez. 1983. Disponível em: http://www.scielo.br/scielo.php?pid=S003489101983000600001\&script=sci_arttext. Acesso em: 10 ago. 2018.

LEFEBVRE, H. Industrialização e urbanização: noções preliminares. In: LEFEBVRE, H. O direito à cidade. São Paulo: Documentos, 1969. p.11-33.

PEREIRA JUNIOR, C. A. (org.). Iguape: princesa do litoral, terra do Bom Jesus, bonita por natureza! São Paulo: Noovha América, 2005.

QEDU. Lista completa de escolas, cidades e estados. São Paulo: Fundação Lemann, 2017. Disponível em: https://qedu.org.br/busca/125-sao-paulo/1464-iguape. Acesso: 2 nov. 2019.

QUILOMBOS DO RIBEIRA. Comunidades quilombolas do Vale do Ribeira. 2011. Disponível em: https://www.quilombosdoribeira.org.br/vale-do-ribeira. Acesso: 30 jul. 2019.

ROCHA, V. L. da; FORESTI, C. O uso do solo urbano e os problemas ambientais da cidade de IguapeSP. In: SIMPÓSIO BRASILEIRO DE SENSORIAMENTO REMOTO. 9., 1998, Santos. Santos, SP. Anais [...]. Santos: INPE, 1998. P. 907-910. Disponível em: http://marte.dpi.inpe.br/col/sid.inpe.br/deise/1999/02.10.15.48/doc/13_89p.pdf. Acesso em: 12 abr. 2019. 
STRIEDER, Cristiane Corrêa; BOSCHETTI, Vânia Regina. As escolas multisseriadas do município de Iguape 1980-2008.

ROLNIK, R. O que é a cidade. São Paulo: Brasiliense, 1988.

YOUNG, E. G. A história de Iguape. Revista do Instituto Histórico e Geographico de São Paulo, São Paulo, v. 8, p. 222-375, 1903. 